\section{Barium Sulfate Crystallization in the Presence of Variable Chain Length Aminomethylenetetraphosphonates and Cations $\left(\mathrm{Na}^{+}\right.$or $\mathrm{Zn}^{2+}$ )}

Eleni Barouda,$\ddagger$ Konstantinos D. Demadis, ${ }^{\star}, \$$ Sandra R. Freeman ${ }^{\dagger}$ Franca Jones, ${ }^{*}, \dagger$ and Mark I. Ogden ${ }^{\dagger}$

Parker Co-operative Research Centre for Integrated Hydrometallurgy Solutions, Nanochemistry Research Institute, Curtin University of Technology, GPO Box U1987, Perth, WA 6845, Australia, and Crystal Engineering, Growth and Design Laboratory, Department of Chemistry, University of Crete, Voutes-Heraklion GR-71003, Crete, Greece

Received July 3, 2006; Revised Manuscript Received November 6, 2006

\begin{abstract}
Barium sulfate is a common scale in oil production installations that is treated and controlled with phosphonate inhibitors. A fundamental understanding of how these inhibitors operate, however, is only slowly emerging. In this paper, we investigate the effect on barium sulfate crystallization of two very similar phosphonate molecules that only differ in their backbone spacing, ethylenediamine- $N, N, N^{\prime}, N^{\prime}$-tetra(methylenephosphonic acid) (EDTMP) and hexamethylenediamine- $N, N, N^{\prime}, N^{\prime}$-tetra(methylenephosphonic acid) (HDTMP). It was found that the inhibitory efficacy of the organic molecules depends on their structural differences but also on the presence of other cations such as $\mathrm{Zn}^{2+}$. It appears that both stereochemical considerations and complexation strength differences between the two phosphonate additives result in different inhibitory powers. In the presence of zinc cations and EDTMP, it is found that inhibition is related to the concentration of uncomplexed ("free") organic.
\end{abstract}

\section{Introduction}

Barium sulfate is a common but unwanted crystallization product (known as barite scale) in the production of oil from off-shore rigs. ${ }^{1-3}$ It is also a simple crystallization system without complications from the presence of polymorphs that has been useful as a model for theoretical and laboratory experimental studies. ${ }^{4-7}$ Phosphonate additives are often used to inhibit either nucleation or growth of barium sulfate in order to avoid scale formation ${ }^{5}$ and several studies have shown that a complex relationship between structure, functional groups, and ionization state of the phosphonate additive impacts on this inhibition. ${ }^{6-8}$ More specifically, the work of Davey's group has suggested that there is a link between the mineral lattice and the functional group spacing (the so-called "lattice matching" criteria) on the additive that dominates inhibitory power. ${ }^{8,9}$ Similarly, for multifunctional molecules it was suggested by Bromley et al. ${ }^{9}$ that only two functional groups were required for inhibition to occur.

Phosphonates have also been used extensively in the field of corrosion control. ${ }^{10-13}$ They are introduced into the system to be protected in the acid form or as alkali metal soluble salts but readily form more stable complexes with other metal cations found in the process stream (most commonly $\mathrm{Ca}^{2+}, \mathrm{Mg}^{2+}, \mathrm{Sr}^{2+}$, or $\mathrm{Ba}^{2+}$ ), depending on the particular application. Research in this area has been stimulated by the need to develop inhibitor formulations that are free from chromates, nitrates, nitrites, inorganic phosphorus compounds, etc. Phosphonates, when blended with certain metal cations and polymers, reduce the optimal inhibitor concentration needed for inhibition due to synergistic effects. ${ }^{14,15}$ Synergism is one of the important effects in the inhibition process and serves as the basis for the development of all modern corrosion inhibitor formulations.

In this paper, we present the results for two phosphonate additives that are very similar in structure yet exhibit funda-

* Corresponding authors. E-mail addresses: franca@ivec.org and demadis@chemistry.uoc.gr.

Curtin University of Technology.

$\doteqdot$ University of Crete. mental structural differences. These are ethylenediamine$N, N, N^{\prime}, N^{\prime}$-tetra(methylenephosphonic acid) (EDTMP) and hexamethylenediamine- $N, N, N^{\prime}, N^{\prime}$-tetra(methylenephosphonic acid) (HDTMP). Their schematic structures and names are given in Figure 1.

Both EDTMP and HDTMP are additives with four phosphonate functional groups that are attached to amine $\mathrm{N}$ atoms through methylene linkages. The only difference is the backbone polymethylene spacing connecting the two $\mathrm{N}$ atoms. If Bromley et al. ${ }^{9}$ are correct and only one of the amine groups "approaches" the barite crystal surface (resulting in two phosphonate groups being adsorbed), the two additives should inhibit to the same degree (see Scheme 1A). However, if both amine groups "approach" surface $\mathrm{Ba}^{2+}$ centers or more than two phosphonate groups are adsorbed, then the two additives will behave differently (Scheme 1B). To validate this hypothesis, we have used standard techniques of conductivity and turbidity as previously employed for such investigations. ${ }^{5,6}$ In addition, the ability of these additives to inhibit in the presence of other ions is assessed. As with previous work in this area, ${ }^{16,17}$ the choice of the standard by which to compare the results is shown to significantly affect the interpretation of the results.

\section{Experimental Section}

Materials. EDTMP (Dequest 2041) and HDTMP (Dequest 2054) are commercial samples from Solutia Inc., St Louis, MO. Their schematic structures and names are given in Figure 1. They can be prepared from their corresponding diamines by the Mannich-type reaction: ${ }^{18}$

$$
\begin{array}{rl}
\mathrm{H}_{2} \mathrm{~N}-\left(\mathrm{CH}_{2}\right)_{n}-\mathrm{NH}_{2}+4 \mathrm{H}_{3} \mathrm{PO}_{3}+4 \mathrm{HCl}+8 \mathrm{HCHO} \rightarrow & \\
\left(\mathrm{H}_{2} \mathrm{O}_{3} \mathrm{PCH}_{2}\right)_{2} \mathrm{~N}-\left(\mathrm{CH}_{2}\right)_{n}-\mathrm{N}\left(\mathrm{CH}_{2} \mathrm{PO}_{3} \mathrm{H}_{2}\right)_{2} & n=2,6
\end{array}
$$

For the experiments described herein, the samples of EDTMP and HDTMP were commercial samples that were purified by repeated recrystallization in acidic $\mathrm{pH}$. This proved to be an effective method of purification, because both additives are sparingly soluble in their acidic form. Spectroscopic characterization (FT-IR and ${ }^{31} \mathrm{P}$ NMR 


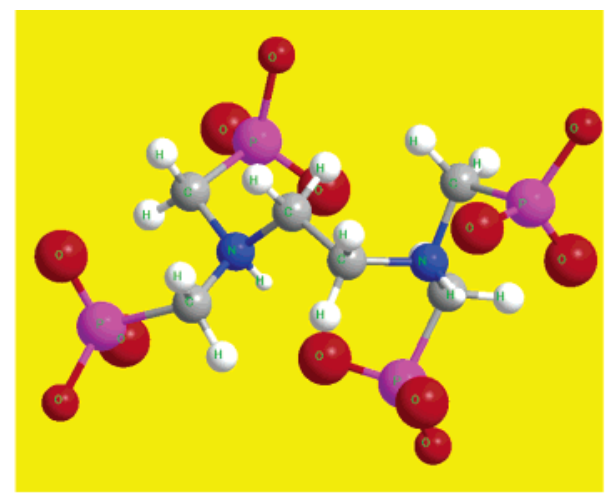

EDTMP

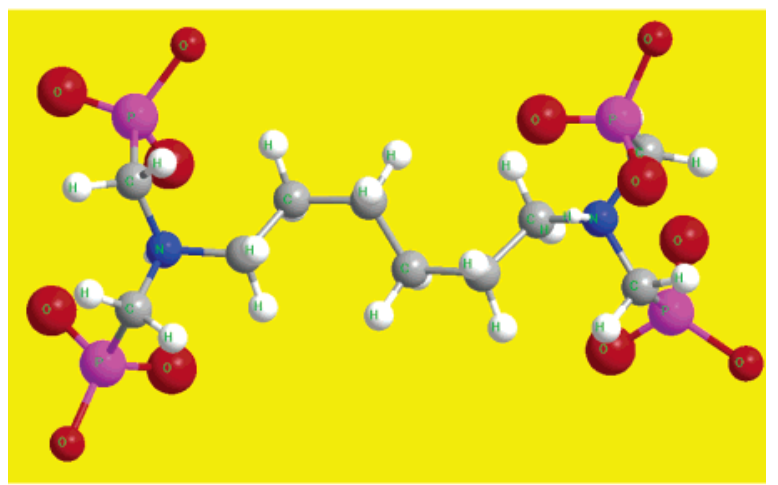

HDTMP

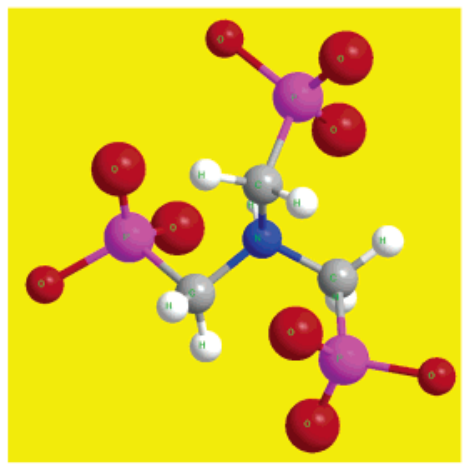

NTMP

Figure 1. Schematic structures of additives used in this work. Abbreviations used in this paper: EDTMP $=$ ethylenediamine$N, N, N^{\prime}, N^{\prime}$-tetra(methylenephosphonate); HDTMP $=$ hexamethylenediamine- $N, N, N^{\prime}, N^{\prime}$-tetra(methylenephosphonate). For comparison, the structure of NTMP, nitrilo-tris(methylenephosphonate), is given as well. Red $=$ oxygen pink $=$ phosphorus; gray $=$ carbon; white $=$ hydrogen; blue $=$ nitrogen .

spectroscopy) of these purified samples gave identical features to those of the prepared in-house samples and showed absence of impurities.

Methods. The conductivity and nephelometry (turbidity) experiments have been described previously. ${ }^{6,16,17}$ Briefly, equimolar amounts of barium chloride and sodium sulfate are mixed together to form barium sulfate (at $\mathrm{pH} \approx 6)$. The additives when present are added to the barium chloride solution prior to the commencement of the reaction. Since these are batch runs, the rates of crystallization are not growth rates and are therefore simply referred to as de-supersaturation rates. The de-supersaturation rate is determined from the linear section of the
Scheme 1. Possible Modes of Adsorption for the Two Phosphonates Being Investigated in This Work: (A)

Bromley et al. ${ }^{9}$ Postulate That Only Two Phosphonate Groups (on the Same Amine Group) Adsorb and (B) Two Phosphonate Groups from Different Amine Groups Adsorb

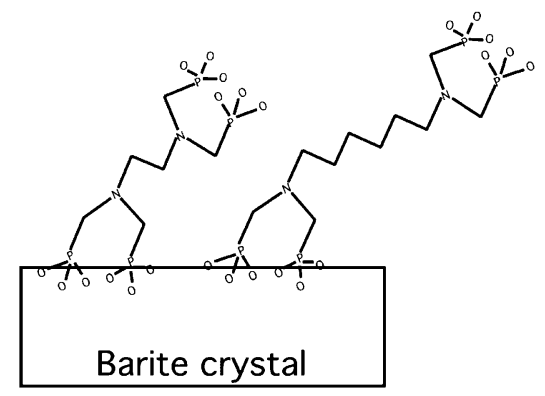

A

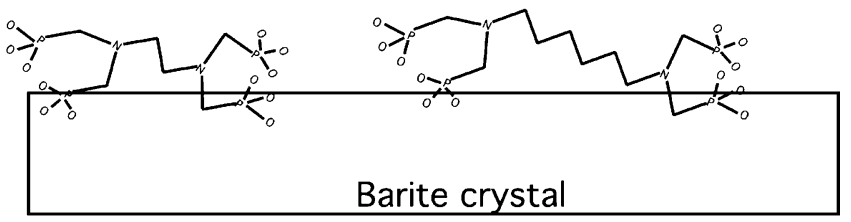

B

conductivity versus time plot (after any induction period). The reaction occurring involves the precipitation of $\mathrm{Ba}^{2+}$ ions with $\mathrm{SO}_{4}{ }^{2-}$ ions to form $\mathrm{BaSO}_{4}$; thus, the change in conductivity is a measure of the crystallization reaction. However, a means of normalizing the conductivity data was necessary due to differences in the de-supersaturation rates when other species are present. It was decided that it was best to plot them as the degree of inhibition. Thus, if crystallization was not at all inhibited, the value should be 0 , while complete inhibition would give $100 \%$. The percent inhibition is given as the normalized difference in the linear de-supersaturation rate times 100 as shown in eq 1 .

$$
\% \text { inhibition }=\left(\left(r_{0}-r\right) / r_{0}\right) \times 100
$$

where $r_{0}$ is the de-supersaturation rate for the control run and $r$ is the de-supersaturation rate in the presence of the additive. The conductivity is measured in $\mathrm{S} \mathrm{cm}^{-1}$, thus the rate of change in conductivity will be $\mathrm{S} \mathrm{cm}^{-1} \mathrm{~s}^{-1}$. The turbidity results did not require such normalization. All tests were performed in duplicate as a minimum.

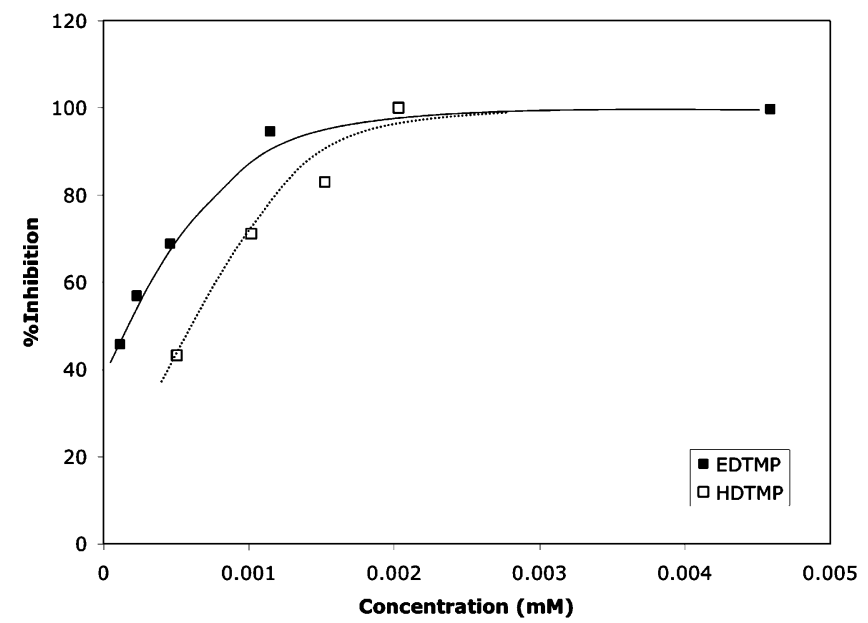

Figure 2. Percent inhibition of barium sulfate precipitation desupersaturation rate vs added concentration of the additives (HDTMP and EDTMP): ( $\square$ ) HDTMP; (ם) EDTMP. Lines drawn to aid reader only. 
0.25 ppm HDTMP

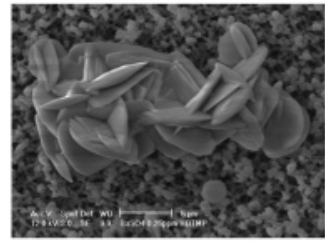

0.75 ppm HDTMP

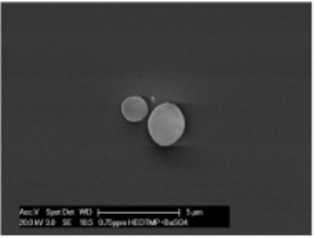

1.0 ppm HDTMP

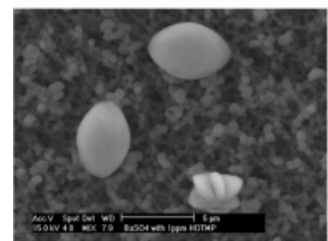

0.25 ppm HDTMP $+\mathrm{Zn}^{2+}$

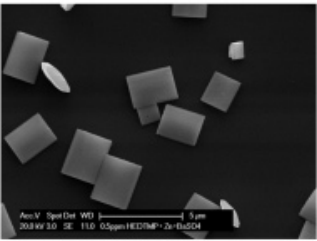

$0.75 \mathrm{ppm}$ HDTMP $+\mathrm{Zn}^{2+}$

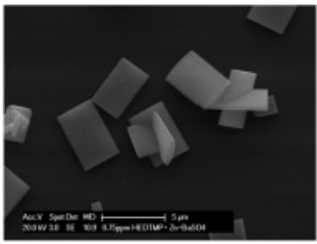

$1.0 \mathrm{ppm}$ HDTMP $+\mathrm{Zn}^{2+}$

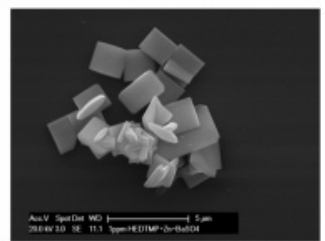

0.25 ppm HDTMP $+\mathrm{Na}^{+}$

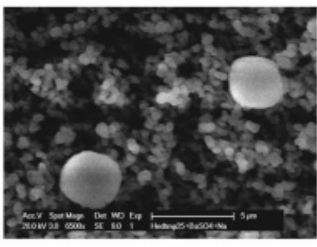

0.75 ppm HDTMP $+\mathrm{Na}^{+}$

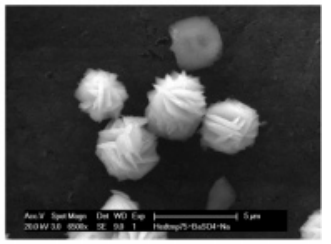

1.0 ppm HDTMP + $\mathrm{Na}^{+}$

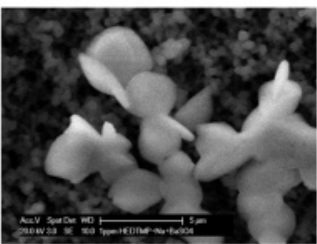

Figure 3. SEM images of barium sulfate precipitated in the presence of HDTMP at various concentrations and with $\mathrm{Zn}^{2+}$ ions or $\mathrm{Na}^{+}$ions present $(0.25 \mathrm{ppm} \equiv 0.0005 \mathrm{mM}, 0.75 \mathrm{ppm} \equiv 0.0015 \mathrm{mM}, 1 \mathrm{ppm} \equiv 0.0020 \mathrm{mM})$.

The results of EDTMP in the presence of calcium cations and in the presence of sodium cations have been previously published and will only be discussed for comparison purposes here. ${ }^{17}$

\section{Results and Discussion}

The results for EDTMP and HDTMP are presented in Figure 2 in terms of their inhibitory efficacy on barium sulfate crystallization by conductivity measurements. As can be seen, in terms of conductivity, EDTMP is able to inhibit barium sulfate crystallization at lower concentrations than HDTMP. However, both inhibit crystallization completely at this supersaturation value at relatively low concentrations $(\sim 0.001 \mathrm{mM}$ for EDTMP and $\sim 0.002 \mathrm{mM}$ for HDTMP).

The morphology of the particles produced in the presence of HDTMP can be seen in Figure 3. The effect of EDTMP on barite morphology has been shown before, ${ }^{5,6,16 \mathrm{~b}}$ producing long fibers at higher concentrations and elongated hexagonal particles at lower concentrations. In comparison, the HDTMP showed a rounded morphology similar to that observed in the presence of the triphosphonate NTMP (nitrilotrimethylenephosphonic acid). ${ }^{7}$ In terms of induction times, EDTMP and HDTMP showed similar trends but at different concentrations, supporting the conductivity results. Roughly, ten times the concentration of HDTMP was required to observe the same effect as that with EDTMP. This is shown in Figure 4. This is probably a consequence of the turbidity probe only detecting particles once they have reached a certain size. In this sense, the turbidity probe is less sensitive than conductivity.

Once $\mathrm{Zn}^{2+}$ ions are present, the question is raised as to what constitutes the "control run". The actual de-supersaturation rates for the different control systems are presented in Table 1.

Clearly, even though the ionic strength has been matched, the presence of $\mathrm{Zn}^{2+}$ appears to have an effect above any ionic strength considerations. We have also noted this previously for calcium ions. ${ }^{16}$ There are two important comparisons that can be made. The first is to take the control as that run with the same concentration of $\mathrm{Zn}^{2+}$ ions in solution or, more specifically, take the ratio

$$
\% \text { inhibition }=\left(\left(r_{\mathrm{Zn}}-r_{\mathrm{Zn}+\text { organic }}\right) / r_{\mathrm{Zn}}\right) \times 100
$$

where $r_{\mathrm{Zn}}$ is the de-supersaturation rate for the control run in the presence of $\mathrm{Zn}^{2+}$ ions (given in Table 1 above) and $r_{\mathrm{Zn}+\text { organic }}$ is the de-supersaturation rate in the presence of the additive and $\mathrm{Zn}^{2+}$ ions. The results are shown in Figure 5 as HDTMP $+\mathrm{Zn}^{2+}$ and EDTMP $+\mathrm{Zn}^{2+}$.

Using this control, we see that for HDTMP $+\mathrm{Zn}^{2+}$ there is actually no concentration for which it inhibits better than HDTMP on its own. On the other hand, since the percent inhibition is not less than zero, we do not get the situation where the rate is greater than that found for $\mathrm{Zn}^{2+}$ ions alone. For EDTMP, we see a different effect, where the inhibition of EDTMP in the presence of $\mathrm{Zn}^{2+}$ is just slightly better than EDTMP alone. Thus, $\mathrm{Zn}^{2+}$ ions appear to have a small inhibitory effect on barite precipitation in the presence of EDTMP based on this comparison.

The SEM images of barite precipitated in the presence of $\mathrm{Zn}^{2+}$ ions and HDTMP show an interesting result (see Figure 3 above). As previously found for EDTA, ${ }^{17}$ the presence of HDTMP with $\mathrm{Zn}^{2+}$ ions causes the barite morphology to revert to that expected for the presence of $\mathrm{Zn}^{2+}$ ions alone. Given that the $\mathrm{Zn}^{2+}$ ions, HDTMP, and $\mathrm{Ba}^{2+}$ ions are all present prior to sulfate addition, this cannot be due to surface adsorption of $\mathrm{Zn}^{2+}$ onto barite particles blocking HDTMP adsorption. We hypothesized that for EDTA, complexation with calcium may have been the cause (implying that the complexed EDTA either did not interact with the barite or was completely incorporated at a 

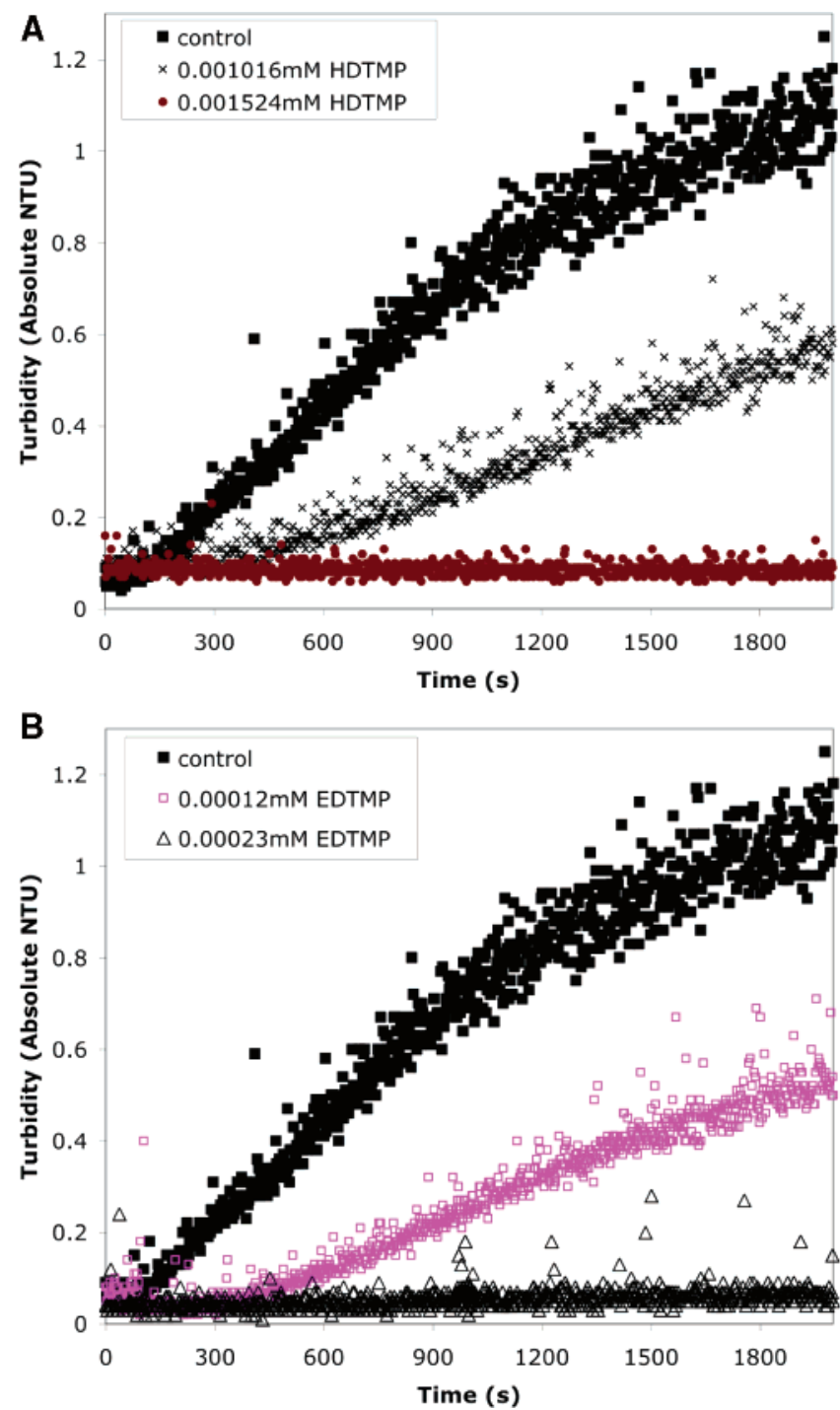

Figure 4. Turbidity (normalized turbidity units, NTU) versus time for barium sulfate precipitation in the presence of (A) HDTMP and (B) EDTMP at different concentrations.

Table 1. Raw De-supersaturation Rates Used for the Different Controls $\left(-1 \times 10^{-8} \mathrm{~S} \mathrm{~cm}^{-1} \mathrm{~s}^{-1}\right)^{a}$

\begin{tabular}{ccc}
\hline $\mathrm{BaSO}_{4}$ & $\mathrm{BaSO}_{4}+\mathrm{Zn}^{2+}(1.25 \mathrm{mM})$ & $\mathrm{BaSO}_{4}+\mathrm{Na}^{+}(3.76 \mathrm{mM})$ \\
\hline 3.34 & 0.727 & 2.90
\end{tabular}

${ }^{a}$ The " -1 " refers to the fact that conductivity decreases as precipitation proceeds.

very early stage of precipitation). ${ }^{17} \mathrm{We}$ hypothesize that something similar is occurring to the HDTMP $+\mathrm{Zn}^{2+}$ ion system.

The second comparison we can make is to compare HDTMP $+(170 \mathrm{ppm}) \mathrm{Zn}^{2+}$ at a particular HDTMP concentration versus HDTMP $+\mathrm{Na}^{+}$at the same HDTMP concentration and with sufficient $\mathrm{Na}^{+}$ions to match the ionic strength (this would then assume that the two systems at the same ionic strength would have the same supersaturation, which may not necessarily be the case). This requires the following $\%$ inhibition to be calculated:

$$
\% \text { inhibition }=\left(\left(r_{\mathrm{Na}}-r_{\mathrm{Na}+\text { organic }}\right) / \mathrm{r}_{\mathrm{Na}}\right) \times 100
$$

where $r_{\mathrm{Na}}$ is the de-supersaturation rate for the control run in the presence of sodium ions (given in Table 1 above) and
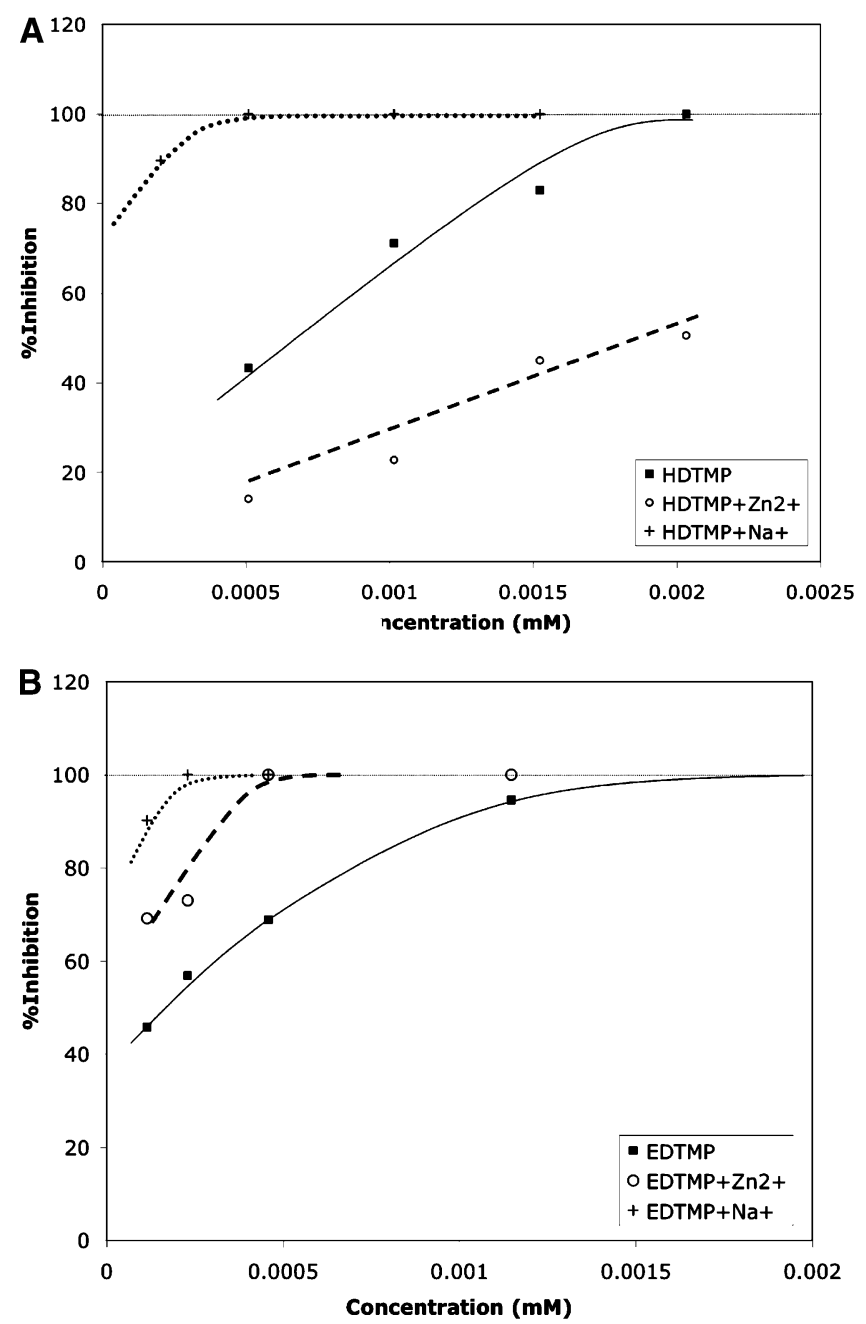

Figure 5. Percent inhibition of barium sulfate precipitation desupersaturation rates versus concentration of additive added and with sodium or $\mathrm{Zn}^{2+}$ ions present: (A) HDTMP and (B) EDTMP. Lines drawn to aid reader only.

$r_{\mathrm{Na}+\text { organic }}$ is the de-supersaturation rate in the presence of the additive and sodium ions. The results are shown in Figure 6 as $\mathrm{HDTMP}+\mathrm{Na}^{+}$and EDTMP $+\mathrm{Na}^{+}$.

In this case, we see that that when $\mathrm{Zn}^{2+}$ ions and EDTMP are present, the precipitation rate is always greater than that in the presence of the equivalent ionic strength of $\mathrm{Na}^{+}$ions. Thus, this comparison suggests that $\mathrm{Zn}^{2+}$ ions do not further inhibit precipitation; rather the presence of $\mathrm{Zn}^{2+}$ ions appears to reduce the efficacy of the phosphonate. This was also observed previously in the presence of $\mathrm{Ca}^{2+}$ ions. ${ }^{17}$ Note that if we had only taken the comparison with $\mathrm{Zn}^{2+}$ ions alone and not with the equivalent $\mathrm{Na}^{+}$ion system, the interpretation would have been that, in the case of EDTMP (the stronger inhibitor), the presence of $\mathrm{Zn}^{2+}$ ions inhibits barite precipitation to a slightly higher level. Only when we compare to the same ionic strength situation do we see that the level of inhibition is actually decreased in the presence of $\mathrm{Zn}^{2+}$ ions. Clearly, it is important to compare results at comparable ionic strengths and supersaturation.

The barium sulfate morphology in the presence of both EDTMP and $\mathrm{Zn}^{2+}$ ions is not dramatically different from that in the absence of $\mathrm{Zn}^{2+}$ or EDTMP (see Figure 6). At the higher concentrations, there is perhaps a lengthening of the $c$-axis, but the morphology is essentially equivalent to the "control" conditions. In the presence of $\mathrm{Na}^{+}$ions and EDTMP, this is 
0.05 ppm EDTMP + $\mathrm{Zn}^{2+}$

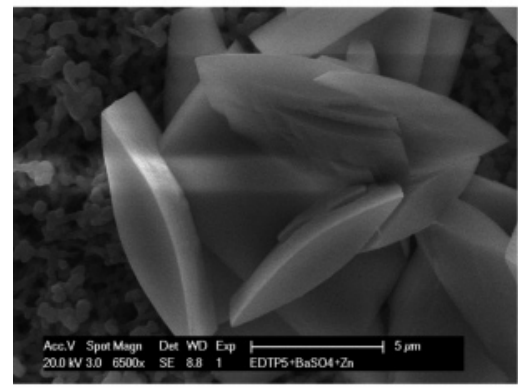

$0.1 \mathrm{ppm}$ EDTMP + $\mathrm{Zn}^{2+}$

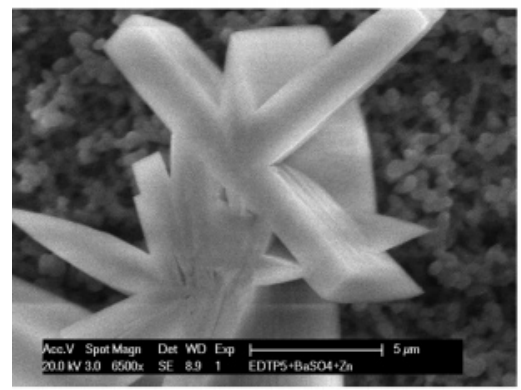

0.05 ppm EDTMP $+\mathrm{Na}^{+}$

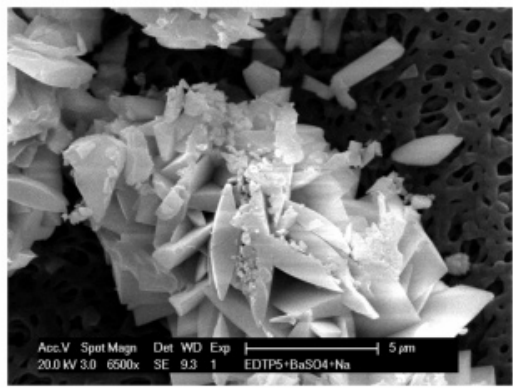

$0.1 \mathrm{ppm}$ EDTMP $+\mathrm{Na}^{+}$

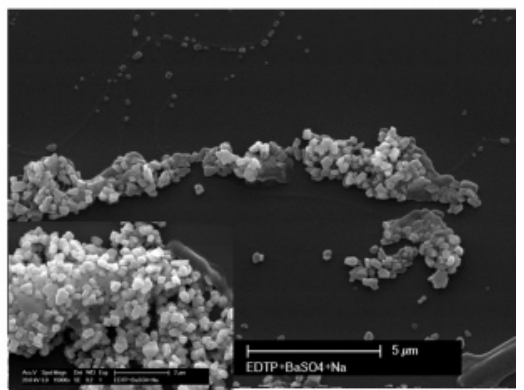

Figure 6. SEM images of barium sulfate particles precipitated in the presence of EDTMP and either $\mathrm{Zn}^{2+}$ or Na ${ }^{+}$ions (inset is at higher magnification; $0.05 \mathrm{ppm} \equiv 0.0001 \mathrm{mM}$ and $0.1 \mathrm{ppm} \equiv 0.0002 \mathrm{mM}$ ).

Table 2. Protonation and Complexation Constants Found from Literature for EDTMP and HDTMP and for the Cations $\mathrm{Ba}^{2+}$ and $\mathrm{Zn}^{2+a}$

\begin{tabular}{ccrlrrr}
\hline & \multicolumn{2}{c}{$\log K$} & & \multicolumn{3}{c}{$\begin{array}{c}\text { complexation data for } \\
\text { EDTMP }(\log K)\end{array}$} \\
\cline { 2 - 3 } \cline { 5 - 7 } species & EDTMP & HDTMP & & species & $\mathrm{Ba}^{2+}$ & $\mathrm{Zn}^{2+}$ \\
\hline LH & 13.00 & 13.30 & & LM & 7.1 & 18.80 \\
LH2 & 9.85 & 13.00 & & LMH & 10.26 & 8.31 \\
LH3 & 7.87 & 6.88 & & LMH2 & 8.54 & 6.06 \\
LH4 & 6.40 & 6.13 & & LMH3 & 7.05 & 4.99 \\
LH5 & 5.12 & 5.29 & & LMH4 & 5.78 & 3.10 \\
LH6 & 3.00 & 4.61 & & &
\end{tabular}

${ }^{a} \mathrm{~L}$ refers to ligand, and $\mathrm{M}$ refers to the metal cation.

true at low additive concentrations, but at higher concentrations where inhibition is significant, the particles are much smaller, and (see Figure 6) it also appears that the particles align to some extent at this concentration.

In terms of the impact of inorganic ions then, the ability to inhibit barium sulfate precipitation is in the order $\mathrm{Na}^{+}<\mathrm{Ca}^{2+}$ $\approx \mathrm{Zn}^{2+}$. When organic additives are also present, the $\mathrm{Ca}^{2+}$ and $\mathrm{Zn}^{2+}$ ions appear to reduce the impact of the organic additive.

In order to try to understand the mode of operation of these additives, we investigated their interaction with the primary cations of interest, barium and zinc. The phosphonates discussed here are able to complex cations in solution. However, this data is not available for both $\mathrm{Ba}^{2+}$ and $\mathrm{Zn}^{2+}$ and for both HDTMP and EDTMP. The data in Table 2 is from the NIST database ${ }^{19}$ and gives the protonation constants for the two additives and the $\mathrm{Ba}^{2+}$ and $\mathrm{Zn}^{2+}$ complexation constants for EDTMP.

Clearly, the protonation of HDTMP and EDTMP is expected to be similar given the similarity in $\log K$ values. At the higher $\mathrm{pH}$ values, it is perhaps expected that the degree of deprotonation for HDTMP will be slightly greater than that for EDTMP given the large $\log K$ values for $\mathrm{LH}_{2}$ and $\mathrm{LH}$. However, because no data exists for the HDTMP complexation with barium or zinc ions, it is impossible to compare the extent of

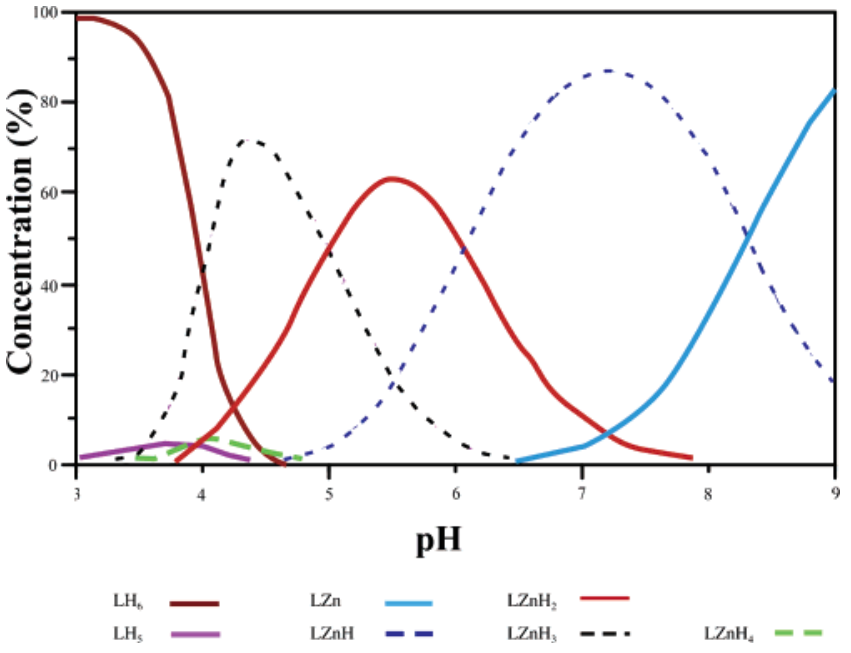

Figure 7. Speciation curve for EDTMP in the presence of zinc ions ( $\mathrm{L}$ refers to fully deprotonated ligand).

complexation with those ions. We can, however, compare the difference between barium and zinc ions for EDTMP. Using this data, we can construct speciation curves (using the Hyss2 program $^{20}$ ) for EDTMP with barium and with zinc ions. The concentration of complexed barium in the presence of EDTMP has already been calculated to be very low; ${ }^{5}$ thus this data will not be re-presented here. In Figure 7, the speciation curve for complexation of zinc ions to EDTMP is shown.

It can be seen that $\mathrm{Zn}^{2+}$ ions alter the concentration of free EDTMP dramatically (i.e., $\leq 20 \%$ of the EDTMP is in the free state if all complexes are added). This means that while the presence of these complexes is not expected to change the supersaturation to any significant degree, the presence of the $\mathrm{Zn}^{2+}-$ EDTMP complexes is expected to reduce the amount of free EDTMP significantly. This can explain the reduction in inhibition if the "active" inhibitor is the free organic additive. 


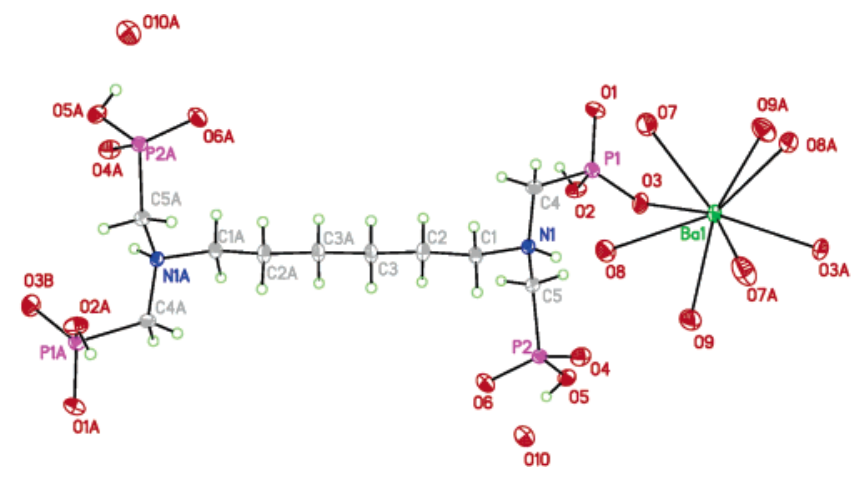

Figure 8. Coordination mode of $\mathrm{Ba}$ in the structure of $\mathrm{Ba}-\mathrm{HDTMP}$, showing the tetraphosphonate connectivity.

The analogous situation could be occurring to an even greater extent in the presence of HDTMP. Furthermore, this suggests that the lack of morphological effect by these organics in the presence of cations is due to the complexed species not being as surface active as the "free" organic. An alternative explanation is that the Zn-additive complex could form the nuclei of the precipitating barium sulfate particles; this would also lead to a diminished effect of the additive (since the additive is not available to adsorb on growth features) leading also to a lack of effect on morphology. However, as yet we have no data in support of this hypothesis. The work of Sorbie and Liang ${ }^{21}$ also suggests that complexation is also important, but they suggest that inhibition by calcium complexes is related to their subsequent incorporation. Since we did not observe increased inhibition when the additives were complexed to calcium, ${ }^{17}$ we do not support this hypothesis.

Further insight into the complexation mode of HDTMP with $\mathrm{Ba}^{2+}$ in the solid state can be obtained by examination of the crystal structure of the $\mathrm{Ba}^{2+}-$ HDTMP material..$^{22}$ The coordination environment of the eight-coordinated $\mathrm{Ba}^{2+}$ center in $\mathrm{Ba}-$ HDTMP can be described as a bicapped octahedron. ${ }^{23}$ Each $\mathrm{Ba}^{2+}$ center is coordinated by six water molecules and two phosphonate oxygens (Figure 8). The bicapped octahedron coordination geometry of $\mathrm{Ba}$ forces the structure to adopt a "zigzag" mode (Figure 9). The Ba centers are the "corners" and the tetraphosphonates are the "arms" of the zigzag chain. These zigzag chains interact with one another via hydrogen bonds. The $\mathrm{Ba}-\mathrm{O}(\mathrm{P})$ bond distance is $2.696(3) \AA$. $\mathrm{Ba}-\mathrm{O}\left(\mathrm{H}_{2} \mathrm{O}\right)$ bond distances range from 2.763(3) to 2.961(3) $\AA$. The $\mathrm{Ba}-\mathrm{Ba}-\mathrm{Ba}$ angles are $149.73^{\circ}$. Interchain $\mathrm{Ba} \cdots \mathrm{Ba}$ distances are $17.114 \AA$ and intrachain $\mathrm{Ba} \cdots \mathrm{Ba}$ distances are $7.657 \AA$. The unit cell dimensions of barite are $a=8.84, b=5.46$, and $c=7.157 \AA$. The interchain $\mathrm{Ba} \cdots \mathrm{Ba}$ distances are just longer than 3 times the $b$-axis length. This means that the HDTMP could be adsorbing on (100) faces and the HDMTP molecule spanning three unit cell lengths in the $b$-axis direction (see Scheme 2). This is more plausible when the following are considered: (i) that EDTMP has already been shown to adsorb favorably onto the (100) face via molecular modeling ${ }^{7}$ and (ii) that the distance between the mid-unit cell barium ion to the corner barium ion,
Scheme 2. Distance of HTDMP Molecule in Relation to the Unit Cell of Barium Sulfate (Not Drawn to Scale)

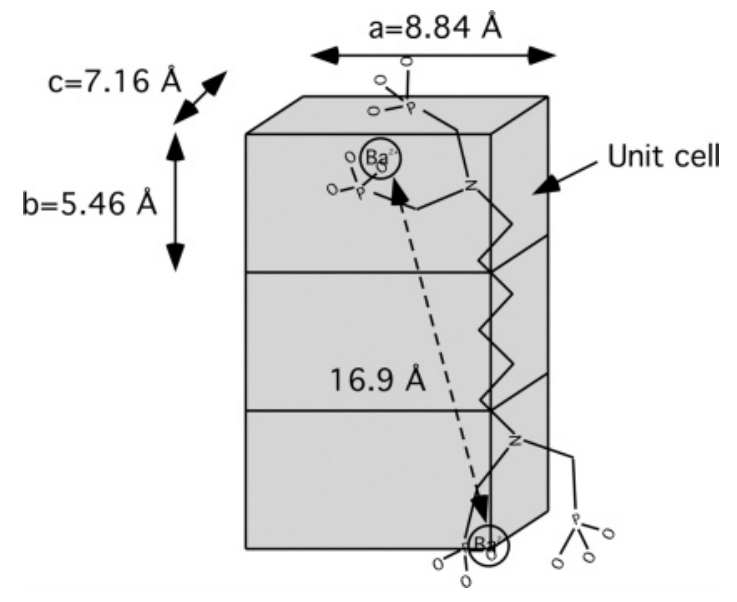

three $b$ axis lengths away, is $16.97 \AA$ (this would replicate the zigzag structure seen in the crystal structure if adsorption were on steps of the (100) face).

It is worth noting that one phosphonate per $\mathrm{N}$ atom is monodeprotonated but non-coordinating to $\mathrm{Ba}^{2+}$. This is clearly seen in Figure 8. The overall coordination mode of HDTMP to $\mathrm{Ba}^{2+}$ is reminiscent of the interaction of HDTMP with the surface of barite, as shown in Scheme 1B.

The structure of $\mathrm{Zn}-$ HDTMP has recently been reported. ${ }^{24}$ It is distinctly different from that of $\mathrm{Ba}-$ HDTMP in several respects: (a) $\mathrm{Zn}^{2+}$ is six-coordinated (distorted octahedron) in contrast to $\mathrm{Ba}^{2+}$, which is a bicapped octahedron. (b) There are no uncoordinated aminomethylenephosphonate arms in the structure of $\mathrm{Zn}$-HDTMP. As mentioned before, one aminomethylenephosphonate arm per $\mathrm{N}$ atom remains non-coordinated in Ba-HDTMP. (c) The structure of Ba-HDTMP is described as zigzag chains linked together by a complicated hydrogenbonding network, whereas the structure of $\mathrm{Zn}-\mathrm{HDTMP}$ is threedimensional. (d) The ligands surrounding the $\mathrm{Zn}$ center are exclusively phosphonate oxygens, whereas $\mathrm{Ba}$ is coordinated by six water molecules and two phosphonate oxygens. $\mathrm{Ba}$ coordination number is higher than that of $\mathrm{Zn}$, as expected, due to the larger ionic radius of the former.

However, while it appears plausible that the crystal structures seen in the solid state do indeed correlate to adsorbed species on the crystal surface, the reason as to why the presence of $\mathrm{Zn}^{2+}$ ions should modify the behavior of the organic additive and its effect on barite precipitation appears to be related to the concentration of free organic in solution, although the lack of inhibitory powers of the $\mathrm{Zn}$ complex may certainly be related to its structural differences from the Ba complex and their incompatibility. As a preliminary test of this, the expected percent inhibition based on a reduced EDTMP concentration was calculated using a simple linear relationship, and these are shown in Table 3. The calculated values correlate well with the obtained experimental values.

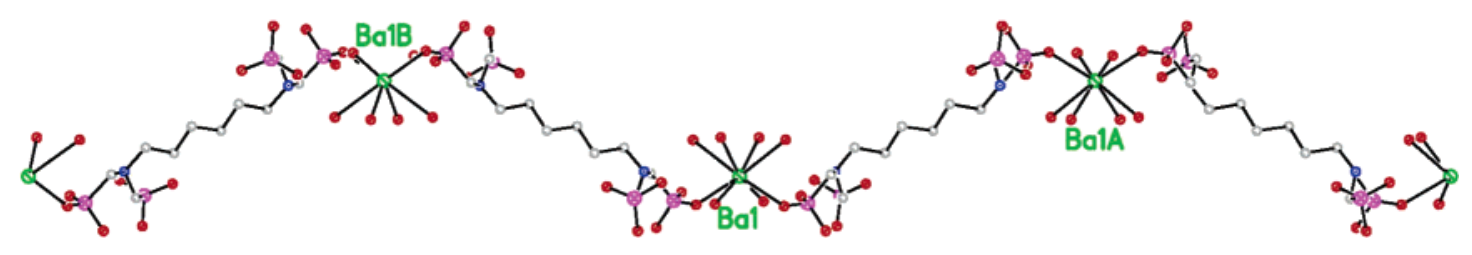

Figure 9. Barium-phosphonate "zigzag" chains in the structure of Ba-HDTMP. 
Table 3. Observed and Calculated Inhibition (\%) for EDTMP in the Presence of Zinc Assuming the Percent Inhibition is Related to the Free EDTMP Concentration

\begin{tabular}{ccc}
\hline $\begin{array}{c}\text { EDTMP } \\
\text { concn }(\mathrm{mM})\end{array}$ & $\begin{array}{c}\text { obsd } \\
\text { inhibition }(\%)\end{array}$ & $\begin{array}{c}\text { calcd } \\
\text { inhibition }(\%)\end{array}$ \\
\hline 0.0002 & 73 & 76 \\
0.0001 & 69 & 73
\end{tabular}

Scheme 3. Schematic Showing Adsorption of All Four Phosphonate Groups for the Organic Additives EDTMP and HDTMP

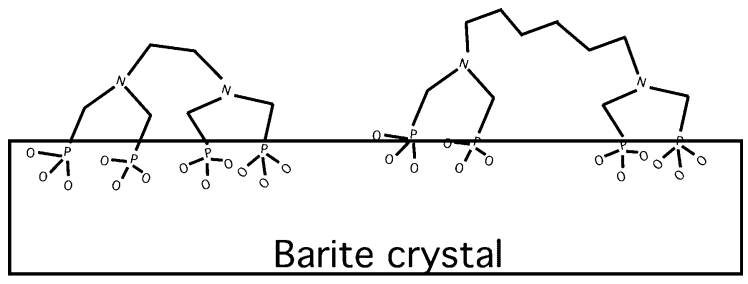

\section{Summary and Conclusions}

In summary, the presence of inorganic ions can have a significant effect on precipitation when additives are present. Interestingly, HDTMP is a slightly weaker inhibitor of barium sulfate than EDTMP despite the similarity of the two additives and the fact that both contain four phosphonate groups. Clearly, the spacing between the amino-bis(methylenephosphonate) moieties of the additive backbone is playing a significant role. This is interesting in itself because Davey et al. ${ }^{8,9}$ suggested that only a minimum length between functional groups was required rather than an optimal length. However, we intend to further probe this by investigating still longer chain linkers. The interpretation of these results is that either the two phosphonate groups adsorbing are not on the same amino group (Scheme 1B) or that more than two functional groups are adsorbing. A schematic of this situation is given in Scheme 3. Molecular modeling of EDTMP ${ }^{7}$ indicates that adsorption of all four phosphonate groups is energetically favorable and is, therefore, possible.

Furthermore, the presence of $\mathrm{Zn}^{2+}$ ions along with HDTMP can be seen to increase the precipitation rate rather than inhibit it when compared with the equivalent ionic strength situation. This effect appears to be due to less inhibitor being available to interact (a solution complexation mechanism). The complexation of zinc ions by EDTMP is shown to be significant, and the case of HDTMP is expected to be analogous. A film of $\mathrm{Zn}-$ HDTMP precipitate has been previously observed to protect carbon steel from excessive corrosion. ${ }^{24}$ The effect of $\mathrm{Zn}^{2+}$ ions on EDTMP inhibitory activity was weaker, and this may be related to a lower complexation strength with $\mathrm{Zn}^{2+}$ ions than that for HDTMP; however, such data is lacking at this point in time. Additionally, in the case of either EDTMP or HDTMP and $\mathrm{Zn}^{2+}$ ions being present, the morphology of barium sulfate was unaffected. This was also observed for EDTA previously and appears to also be related to the complexation of the organic additive with the inorganic ion. It is not known, however, how general this phenomenon is. Questions such as whether all divalent cations weaken the effect of organic additives or about the effect of trivalent cations are expected to further drive this research.

Acknowledgment. S.R.F., F.J., and M.I.O. gratefully acknowledge that this research has been supported under the Australian Government's Cooperative Research Centre (CRC) Program, through the Parker CRC for Integrated Hydrometallurgy Solutions. The General Secretariat of Science \& Technology and the Department of Chemistry, University of Crete, are acknowledged for funding, and Drs. Raphael G. Raptis and
Hong Zhao of the Department of Chemistry, University of Puerto Rico at Rio Piedras, are acknowledged for help with data collection on Ba-HDTMP (K.D.D.).

\section{References}

(1) Sorbie, K. S.; Mackay, E. J. J. Pet. Sci. Eng. 2000, 27, 85.

(2) Breen, P. J.; Downs, H. H.; Diel, B. N. R. Soc. Chem. (Spec. Publ.) 1991, 97, 186

(3) Graham, G. M.; Boak, L. S.; Sorbie, K. S. Int. Symp. Oilfield Chem., Soc. Pet. Eng., U.S.A. 1997, SPE37273.

(4) Schwarzer, H.-C.; Peukert, W. Chem. Eng. Technol. 2002, 25 (6), 657.

(5) Jones, F.; Clegg, J.; Oliveira, A.; Rohl, A. L.; Ogden, M. I.; Parkinson, G. M. CrystEngComm 2001, 40, 1 .

(6) Jones, F.; Stanley, A.; Oliveira, A.; Rohl, A. L.; Reyhani, M. M.; Parkinson, G. M.; Ogden, M. I. J. Cryst. Growth 2003, 249, 584

(7) Jones, F.; Richmond, W. R.; Rohl, A. L. J. Phys. Chem. B 2006, 110,7414

(8) Coveney, P. V.; Davey, R. J.; Griffin, J. L. W.; He, Y.; Hamlin, J. D.; Stacckhouse, S.; Whiting, A. J. Am. Chem. Soc. 2000, 122, 11557.

(9) Bromley, L. A.; Cottier, D.; Davey, R. J.; Dobbs, B.; Smith, S.; Heywood, B. R. Langmuir 1993, 9, 3594.

(10) Demadis, K. D.; Katarachia, S. D.; Koutmos, M. Inorg. Chem. Commun. 2005, 8, 254.

(11) Demadis, K. D.; Lykoudis, P.; Raptis, R. G.; Mezei, G. Cryst. Growth Des. 2006, 6, 1064.

(12) Telegdi, J.; Shaglouf, M. M.; Shaban, A.; Kármán, F. H.; Betróti, I.; Mohai, M.; Kálmán, E. Electrochim. Acta 2001, 46, 3791.

(13) Felhósi, I.; Kálmán, E. Corros. Sci. 2005, 47, 695.

(14) Kuznetsov, Y. I.; Kazanskaya, G. Y.; Tsirulnikova, N. V. Prot. Met. 2003, 39, 120.

(15) Sastri, V. S. Corrosion Inhibitors: Principles and Applications; John Wiley \& Sons: Chichester, U.K., 1998; p 720.

(16) Jones, F.; Oliveira, A.; Parkinson, G. M.; Rohl, A. L.; Stanley, A.; Upson, T. J. Cryst. Growth 2004, 262, 572.

(17) Jones, F.; Oliveira, A.; Parkinson, G. M.; Rohl, A. L.; Stanley, A.; Upson, T. J. Cryst. Growth 2004, 270, 593.

(18) Moedritzer, K.; Irani, R. R. Inorg. Chem. 1966, 31, 1603.

(19) Martells, A. E.; Smith, R. M. NIST critically selected stability constants of metal complexes, V6.0; National Institute of Standards and Technology: Gaithersburg, MD, 2001.

(20) Alderighi, L.; Gans, P.; Ienco, A.; Peters, D.; Sabatini, A.; Vacca, A. Coord. Chem. Rev. 1999, 184, 311.

(21) Sorbie, K. S.; Laing, N. Society of Petroleum Engineers, 2004, paper SPE87470.

(22) Complete details on the synthesis and structural characterization of $\mathrm{M}-\operatorname{HDTMP}(\mathrm{M}=\mathrm{Mg}, \mathrm{Ca}, \mathrm{Sr}, \mathrm{Ba})$ will be given elsewhere in a future publication. However, for the purposes of the present paper, we report some details. A quantity of $\mathrm{BaCl}_{2} \cdot 2 \mathrm{H}_{2} \mathrm{O}(0.566 \mathrm{~g}, 2.315$ $\mathrm{mmol})$ is dissolved in deionized water $(\sim 50 \mathrm{~mL})$, and HDTMP (4 $\mathrm{mL}$ of a $50 \%$ solution of the sodium salt of HDTMP, $2.315 \mathrm{mmol}$ ) is added to it dropwise under vigorous stirring. Solution $\mathrm{pH}$ is finally adjusted to 2.2, and the clear colorless solution is left to stand at room temperature. After a couple days single crystals of Ba-HDTMP appear. All reactions attempted precipitated crystalline material within the first days, but crystallization can be allowed to proceed over several days for higher final yields. The precipitates are isolated by filtration and air- or oven-dried. Yields are typically $>70 \%$ and can reach $80 \%$ depending on crystallization time. Satisfactory elemental analyses were obtained for all products. Synthetic efforts at higher $\mathrm{pH}$ regions resulted in noncrystalline powder products that were difficult to characterize satisfactorily. FT-IR spectra of Ba-HDTMP displays a multitude of bands in the region $1100-1270 \mathrm{~cm}^{-1}$ assigned to the $\mathrm{P}=\mathrm{O}$ stretch. $\mathrm{X}$-ray diffraction data were collected on a SMART $1 \mathrm{~K}$ CCD diffractometer at 293(2) $\mathrm{K}$ with Mo $\mathrm{K} \alpha(\lambda=$ $0.71073 \AA$ ). Crystallographic details: colorless rectangular plates $\left(0.22 \times 0.18 \times 0.10 \mathrm{~mm}^{3}\right)$, monoclinic, space group $C 2 / c$, with $a=$ 14.084(4) $\AA, b=6.0158(15) \AA, c=33.793(9) \AA, \beta=100.717(4)^{\circ}$, $V=2813.3(12) \AA^{3}, Z=4, d_{\text {calcd }}\left(\mathrm{g} / \mathrm{cm}^{3}\right)=1.822$, total reflections 8568 , refined reflections $\left.\left(I_{\text {net }}>2 \sigma I_{\text {net }}\right)\right) 2982$, number of parameters $175, R=0.0345$ (0.0361, all data), $R_{\mathrm{w}}=0.0905$ (0.0913, all data), $\mathrm{GOF}=1.281$. Further details can be obtained from CCDC (www.ccdc.cam.ac.uk/data_request/cif) by quoting the ref no. 293464.

(23) Muetterties, E. L.; Guggenberger, L. J. J. Am. Chem. Soc. 1974, 96, 1748 .

(24) Demadis, K. D.; Mantzaridis, C.; Raptis, R. G.; Mezei, G. Inorg. Chem. 2005, 44, 4469. 